International Journal of Current Advanced Research

ISSN: O: 2319-6475, ISSN: P: 2319 - 6505, Impact Factor: SJIF: 5.995

Available Online at www.journalijcar.org

Volume 6; Issue 4; April 2017; Page No. 3357-3360

DOI: http://dx.doi.org/10.24327/ijcar.2017.3360.0272

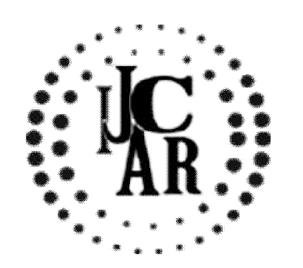

Research Article

\title{
PRECLINICAL EVALUATION OF HERBAL PLANT IN POTASSIUM OXONATE INDUCED HYPERURICEMIA IN MICE
}

\author{
${ }^{*}$ Pooja .S.Bhandare ${ }^{1}$, Ziyaurrahman A.R ${ }^{2}$., Narkhede $S^{3}$ and Dipti Kaspate ${ }^{3}$ \\ ${ }^{1}$ Department of Pharmacology, GIPER, Limb, Satara \\ 2Department of Pharmacology, M.C.E. Society's Allana College of Pharmacy, \\ University of Pune, India \\ ${ }^{3}$ Deprment of Pharmacology, All India Shri Shivaji Memorial Society's College of Pharmacy, \\ University of Pune, India
}

\section{A R T I C L E I N F O}

\section{Article History:}

Received $14^{\text {th }}$ January, 2017

Received in revised form $20^{\text {th }}$ February, 2017

Accepted $10^{\text {th }}$ March, 2017

Published online $28^{\text {th }}$ April, 2017

\section{Key words:}

XOD-Xanthine oxidase, XDH-Xanthine dehydrogenase, AVLE-Aqueous leaves extract of Adhatoda vasaka, PO-Pottasium Oxonate.

\begin{abstract}
A B S T R A C T
Objective: The objective of the study to perform Preclinical Evaluation Of Herbal Plant In Potassium Oxonate Induced Hyperuricemia In Mice.

Method: The present study was undertaken to investigate anti-gouty arthritic activity of aqueous leaves extract of Adhatoda vasaka using Potassium Oxonate induced hyperuricemia in mice. Potassium oxonate (PO) induced hyperuricemia in mice were determined by in vivo experiments. $\mathrm{PO}$ causes hyperuricemia in $1 \mathrm{~h}$ after ip administration thus mice were administered PO followed by AVLE and standard drug treatment of Allopurinnol study conducted for 7 days finally measuring the serum levels of uric acid, xanthine oxidase, xanthine dehyrogenase, etc.

Results: The evaluation of anti-gouty arthritic potential by oral administration of AVLE $(100-400 \mathrm{mg} / \mathrm{kg})$ evoked a significantly decreased the serum levels of uric acid, xanthine oxidase (XOD), xanthine dehydrogenase (XDH) in treated mice.

Conclusions: The results obtained in this study indicate that AVLE possesses potential anti-gouty arthritic activity. Finally, the study concluded that in AVLE the flavonoidal constituitents impart enzyme inhibitory activity thus reducing levels of xanthine oxidase, xanthine dehyrogenase and serum uric acid.
\end{abstract}

Copyright $\mathrm{C} 2017$ Pooja .S.Bhandare et al. This is an open access article distributed under the Creative Commons Attribution License, which permits unrestricted use, distribution, and reproduction in any medium, provided the original work is properly cited.

\section{INTRODUCTION}

Adhatoda vasica (L.) Nees (family Acanthaceae) is a shrub 1$2.5 \mathrm{~m}$ high with opposite ascending branches the leaves are simple, opposite, $7-19 \mathrm{~cm}$ long and 4-7 $\mathrm{cm}$ wide. The flowers are white, pink or purple. The plant grows throughout the Indian peninsula up to an altitude of $1300 \mathrm{~m}$. The names Adhatoda zeylanica Medic and Justicia adhatoda L. are used synonymously. It is also known under the common name Malabar nut tree and the Sanskrit name Vasaka. The plant has been used in the indigenous system of medicine in India for over 2000 years. It is a well-known drug in Ayurvedic and Unani medicine (Manjunath, 1948). The leaves was used for stomach catarrh with constipation, gout, urinary stone (Madaus, 1938) and warmed leaves used externally for rheumatic pains and dislocation of joint (Rao and Jamir, 1982). Anti-oxidant and radical scavenging activity (Srinivasarao et al., 2006) Anti-inflammatory effect (K.alam et al., 2011)

*Corresponding author: Pooja .S.Bhandare

Department of Pharmacology, GIPER, Limb, Satara
However, its anti-gouty arthritic potential has not been scientifically explored. Disturbances in this metabolic system are associated with several disease conditions. and treatment of hyperuricemia and gout is based on the experience of traditional medicine systems (Theoduloz et al.,1988; Chiang et al., 1994; Guerrero and Guzman, 1998; Owen and Johns, 1999; Kong et al., 2000), their uses in modern medicine suffer from the lack of scientific evidences. Attention has been focused on identifying their phytochemicals, which possess ability to inhibit $\mathrm{XDH} / \mathrm{XO}$ activities andthereby reduce the urate levels. Flavonoids have been shown to be inhibitors of the activityof XO in in vitro study (Nagao et al., 1999). Thus, there are several preclinical studies that can be employed for the evaluation of the antigouty arthritic potential of a compound. Therefore, in present study, an attempt has been made to evaluate Adhatoda vasica aqueous leaves extract (AVLE) for its Anti-gouty arthritic activity.

\section{MATERIALS AND METHODS}

\section{Drug material}

Pottasium oxonate was procured from Sigma-aldrich, USA. 


\section{Chemicals and drugs}

1. AllopurinolTablets:Zyloric ${ }^{\circledR}$ GlaxosmithKlinePharma ceuticals, Batch no-N385

2. Adhatoda vasica aqueous leaves extract (AVLE) was obtained from Saiba Industries Gujrat, India.

\section{Animals}

The study was approved by Institute's animal ethical committee and confirmed to national guidelines on the care and use of laboratory animals (CPCSEA/IAEC/PC-10/072K8). Swiss albino mice 25-30 gms were obtained from Yash farms, Pune used for the study. The animals were maintained at $25 \pm 2{ }^{\circ} \mathrm{C}$ in the Institute's animal house with food (nutrivet, Pune, India) and water ad libitum.

\section{Selection of dose}

AVLE was weighed accurately and prepared appropriate stock solution $(100 \mathrm{mg} / \mathrm{kg}, 200 \mathrm{mg} / \mathrm{kg}, 400 \mathrm{mg} / \mathrm{kg})$ using distilled water as a vehicle. The drug solutions were prepared fresh daily.

\section{Anti-Gouty Arthritic Activity}

\section{Potassium oxonate (PO) induced Gout in mice}

Animals: Swiss male albino mice, 25-30 g, will be required. Drug: Aqueous leaves extract of Adhatoda vasica Inducing agent: Potassium oxonate (PO)

\begin{tabular}{cc}
\hline Groups & Dose and Route \\
\hline Control & $0.9 \%$ saline solution $(1 \mathrm{ml} / \mathrm{kg})$ \\
PO control & $\begin{array}{c}\text { Potassium oxonate }(250 \mathrm{mg} / \mathrm{kg}, \mathrm{i} . \mathrm{p},) \\
\text { Standard }\end{array}$ \\
$\begin{array}{c}\text { Potassium oxonate }(250 \mathrm{mg} / \mathrm{kg}, \mathrm{i} . \mathrm{p},)+\text { Allopurinol }(10 \mathrm{mg} / \mathrm{kg} \\
\text { orally) on } 1 \mathrm{st}, 3 \mathrm{rd} \text { and } 7 \text { th day }\end{array}$ \\
AV 100 & $\begin{array}{c}\text { Potassium oxonate }(250 \mathrm{mg} / \mathrm{kg}, \mathrm{i} . \mathrm{p},)+\text { Aqueous extract of } \\
\text { Adhatoda vasica }(100 \mathrm{mg} / \mathrm{kg}) \text { on } 1 \mathrm{st}, 3 \mathrm{rd} \text { and } 7 \text { th day }\end{array}$ \\
AV 200 & $\begin{array}{c}\text { Potassium oxonate }(250 \mathrm{mg} / \mathrm{kg}, \mathrm{i} . \mathrm{p},) \text { Aqueous extract of Adhatoda } \\
\text { vasica }(200 \mathrm{mg} / \mathrm{kg}) \text { on } 1 \mathrm{st}, 3 \mathrm{rd} \text { and } 7 \text { th day }\end{array}$ \\
AV 400 & $\begin{array}{c}\text { Potassium oxonate }(250 \mathrm{mg} / \mathrm{kg}, \text { i.p, })+\text { Aqueous extract of } \\
\text { Adhatoda vasica }(400 \mathrm{mg} / \mathrm{kg}) \text { on } 1 \mathrm{st}, 3 \mathrm{rd} \text { and } 7 \text { th day }\end{array}$ \\
\hline
\end{tabular}

\section{Procedure}

Divide mice into six groups $(n=6)$. Withdraw food, but not water from all the animals on $1.5 \mathrm{~h}$ before the final drug administration on the $7^{\text {th }}$ day of study, inject intraperitonally (i.p) with potassium oxonate $(250 \mathrm{mg} / \mathrm{kg})$ to increase the serum urate level. Group I control which will receive saline, Group II hyperuricemic control will orally receive $0.9 \%$ saline $(1 \mathrm{ml} / \mathrm{kg})$ solution for 1,3 and 7 days, respectively. Group III will serve as Standard will receive orally Allopurinol $(10 \mathrm{mg} / \mathrm{kg}$ ) for 1,3 and 7 days, respectively. AV 100, AV 200 and AV 400and will receive extract of Adhatoda vasica at 100,200 and $400 \mathrm{mg} / \mathrm{kg}$ respectively for 1,3 and 7 days, respectively. Collect whole blood samples $1 \mathrm{~h}$ after final drug administration. Blood was allowed to clot, Centrifuge to obtain the serum. Measuring serum parameters such ac Uric acid, Xanthine oxidase (XOD), Xanthine dehydrogenase (XDH) levels. ${ }^{1,2}$

\section{RESULTS}

The values were calculated as mean \pm SEM The significance of the difference of the mean value with respect to control group was analyzed by one way ANOVA followed by Dunnet's ttest using using software Graphpad Prism 6.0. $\mathrm{P}<0.01$ or above was considered to be significant. ${ }^{5,6}$
Study of the effect of Adhatoda vasica in potassium oxonate induced hyperuricemia in mice:

The results obtained in table 1 below for serum uric acid, $\mathrm{XOD}, \mathrm{XDH}$ and of liver homogenate Control rats (group I) showed normal concentrations of serum uric acid, XOD and XDH activity lower than all other groups. Negative control rats (group II) showed the highest values for serum uric acid, XOD and XDH activity which were significantly higher than the corresponding values obtained for control animals with $\mathrm{P}<0.001$. Rats treated with AVLE 100 (group III), AVLE 200(group IV), AVLE 400 (group V) showed significant decrease in serum uric acid with $\mathrm{P}<0.001$ than negative control and significant $\mathrm{XOD}$ and $\mathrm{XDH}$ activity with $\mathrm{P}<0.001$ and $\mathrm{P}<0.01$ for $\mathrm{XOD}$ and $\mathrm{P}<0.001$ and $\mathrm{P}<0.001$ for $\mathrm{XDH}$ for groups III, IV and $\mathrm{V}$ respectively. However it can be noted that in comparison to the negative control all the test groups show notable inhibition in XOD and $\mathrm{XDH}$ activity. In mice treated with standard allopurinol (group VI) it can be observed that allopurinol almost completely inhibits the rise in uric concentration and XOD, with values similar to the control, with a slightly significant $\mathrm{XDH}$ activity with $\mathrm{P}<0.01$. It can be observed that AVLE 400 show a slightly better XOD inhibition as compared to than allopurinol standard.

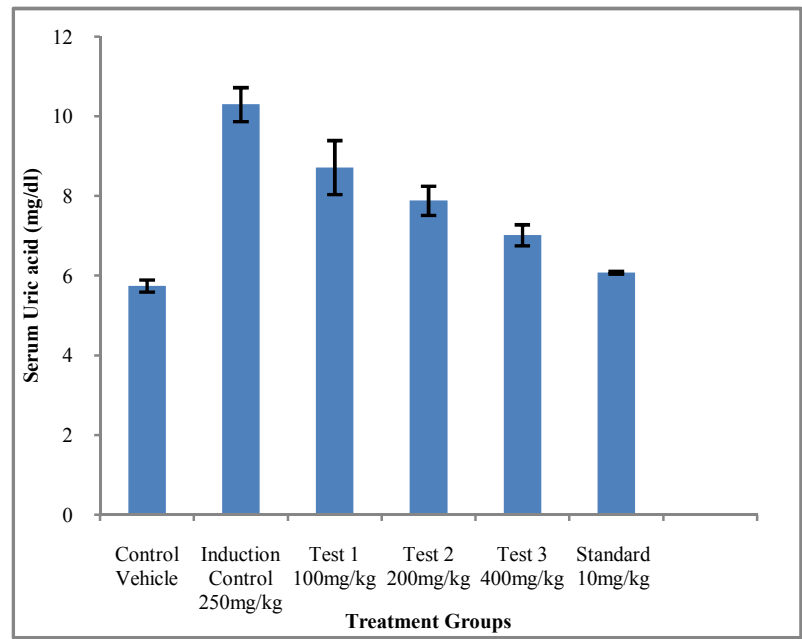

Fig 1 Effect of vehicle, PO, AVLE 100, AVLE 200, AVLE 400 and allopurinol on uric acid levels

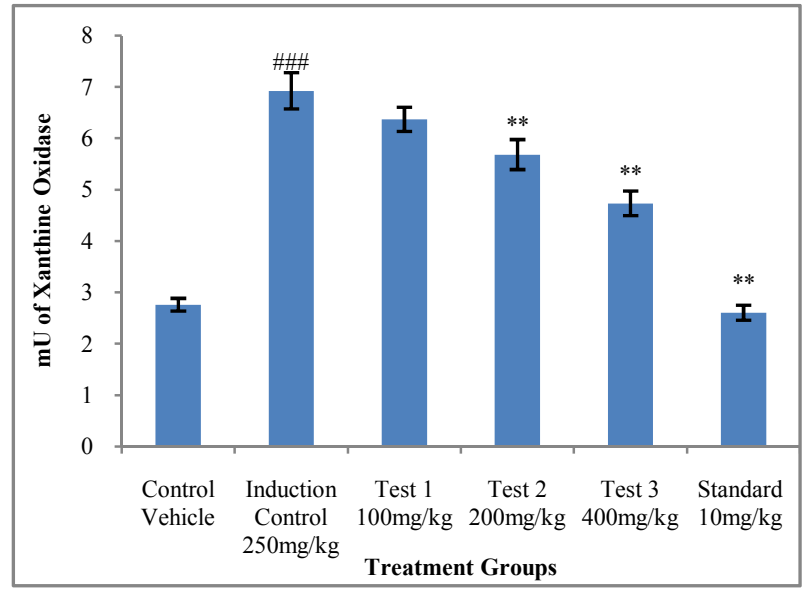

Fig 2 Effect of vehicle, PO, AVLE 100, AVLE 200, AVLE 400 and allopurinol on XOD levels 


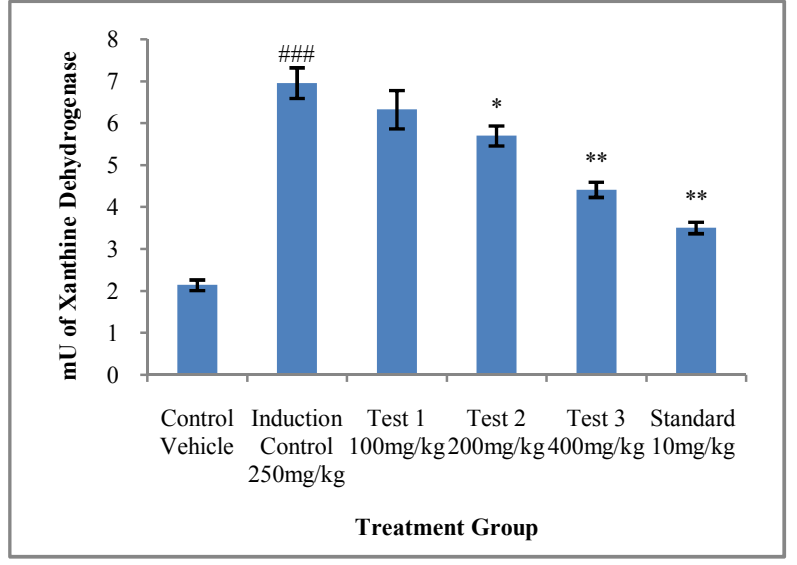

Fig 3 Effect of vehicle, PO, AVLE 100, AVLE 200, AVLE 400 and allopurinol on XDH levels

Table 1Effect of AVLE ON serum uric acid, XOD, XDH levels

\begin{tabular}{cccc}
\hline $\begin{array}{c}\text { Treatment } \\
\text { Groups }\end{array}$ & Serum uric acid & XOD & XDH \\
\hline Normal control & $5.74 \pm 0.152$ & $2.76 \pm 0.123$ & $2.141 \pm 0.1266$ \\
PO control & $10.3 \pm 0.4258$ & $6.923 \pm 0.352$ & $6.961 \pm 0.3636$ \\
ALLOPURINOL & $6.073 \pm 0.03528^{* *}$ & $2.605 \pm 0.144^{* *}$ & $3.5058 \pm 0.1358^{* *}$ \\
AVLE 100 & $8.716 \pm 0.679$ & $6.366 \pm 0.234$ & $6.328 \pm 0.4575$ \\
AVLE 200 & $7.883 \pm 0.3655^{*}$ & $5.683 \pm 0.2926 *$ & $5.7 \pm 0.2394$ \\
AVLE 400 & $7.016 \pm 0.2651^{* *}$ & $4.733 \pm 0.2404^{* *}$ & $4.416 \pm 0.1797 *$ \\
\hline
\end{tabular}

Values are expressed as mean \pm S.E.M. $n=6$. Significant values were compared with

$* \mathrm{P}<0.05, * * \mathrm{P}<0.01, * * * \mathrm{P}<0.001$ ANOVA followed by

Dunnetts test, all groups compared to PO control group.

\section{DISCUSSION}

Gout is a metabolic disorder associated with an excess of circulating uric acid resulting in the deposition of monosodium urate crystals (MSU) in tissues. This hyperuricaemia can occur via uric acid under-excretion or overproduction, and can be readily determined in most patients.A number of reversible factors contribute to increased urate production, including a high purine diet, obesity and regular alcohol consumption (Bieber and Terkeltaub, 2004; Choi et al., 2004). After formation, the MSU crystals may be deposited in joints, usually in the big toe or ankle, causing neutrophil infiltration, swelling and excruciating pain (Desaulniers et al., 2001). Estimations from the Third National Health and Nutrition Examination Survey (NHANES III) indicate that $0.5 \%$ of the total population has suffered from a gout attack. In addition, gout is currently considered to be the most common form of inflammatory arthritis in men over 40 years old. exceeding rheumatoid arthritis (Lawrence et al., 1998; Weaver, 2008). The options for the treatment of chronic gout are allopurinol, which is an inhibitor of the xanthine oxidase enzyme, probenecid, which is a uricosuric drug that stimulates the renal excretion of uric acid, and non-steroidal anti-inflammatory drugs (NSAIDs), such as indomethacin, that inhibit COX enzyme activity (Cronstein and Terkeltaub, 2006; Terkeltaub, 2010). Another drug that has been used to treat gout attacks is colchicine, which is an alkaloid derived from the autumn crocus Colchicum autumnale (Roberge et al., 1993). However, approximately $50 \%$ of patients are noncompliant with the prescribed medication, especially if they are having recurring gout flares (Gaffo and Saag, 2010). Moreover, each of these agents is associated with risks, potentially severe adverse effects and drug-drug interactions. Thus, many gout patients end up opting for treatments based on folk medicine (Terkeltaub, 2010). The disease has a very long course of relapses and remissions and thus causes gross deformity (Winstanley et al. 1996). Treatment for Arthritis is mostly a lifetime process and hence above mentioned drawbacks need to be addressed. Some side effects are bone marrow suppression, cardiovascular complications, hepatotoxicity, renal impairment, etc.

Though a large number of new drugs and therapies have been developed over the past few decades, even today, no ideal drug treatment is available to completely cure or check the progress of this disease. Hence, many of arthritic patients commonly prefer complementary and alternative medicines (Shankaranarayanan et al.., 2009) which emphasize the need of a cost effective drug with minimal side effects. The objective of the present study was to evaluat the antigouty arthritic activity of the Aqueous leaves extract of Adhatoda vasica Nees. Adhatoda vasica Nees. (Acanthaceae) is commonly known as "Malabar nut". The decoction of Adhatoda vasica Nees. is used in rheumatism. Earlier studies also reports the presence of phytosterols like alkaloids, carbohydrates, proteins, and trace elements are present in the leaves Adhatoda vasica Nees

In present study $A$. vasica aqueous leaves extract (AVLE) was used. In acute oral toxicity study the extract was found to be safe up to the dose of $2000 \mathrm{mg} / \mathrm{kg}$. From this data, three doses of 100,200 and $400 \mathrm{mg} / \mathrm{kg}$ were selected for testing dose dependant anti-gouty arthritic potential of AV. The preliminary phytochemical analysis results showed the prominent presence of alkaloids, triterpenoids, saponins, tannins, glycosides and flavonoids in AVLE. The antiarthritic effect of AVLE was confirmed by measuring the, serum levels of uric acid, XOD, XDH etc clinical endpoints for evaluating the efficacy of any anti-gouty arthritic agent. AVLE showed significant anti-gouty arthritic effect in a dose dependant manner. It was found that $200,400 \mathrm{mg} / \mathrm{kg}$ dose of AVLE was effective.

The present study results indicate that AVLE possesses significant anti-hyperuricemic activities. The effect might be due to potential phytochemicals found to be present in preliminary phytochemical analysis such as phytosterols, alkaloids, triterpenoids, saponins, tannins and flavonoids. The ideal requirement of an Anti-gouty arthritic agent includes anti-inflammatory and anti-hyperuricemic properties. The current research work indicates that Adhatoda vasica aqueous leavese extract demonstrated significant antihyperuricemic and anti-inflammatory activity. This suggests that Adhatoda vasica aqueous leaves extract could be a valuable addition to the current anti-arthritic therapies. Moreover, these studies strongly validate the claims of the tribal use of this plant as an anti-arthritic agent. Also it paves way for further investigation of the chemical constituents responsible for the activity.

\section{CONCLUSION}

All the characterstic features of gouty arthritis such as lowering the raised enzymes levels of uric acid, XOD, XDH where restored by AVLE treatment in the study protocol and hence can be used for treatment protocol. From the present work, it can be concluded that Adhatoda vasica leaves extract 
(AVLE) might act as an anti-gouty arthritic agent, with antihyperuricemic activity. The phytochemicals like alkaloids, flavonoids, triterpenoids, tannins, proteins, glycosides, vitamin $\mathrm{C}$ etc. Present findings support the tribal use of Adhatoda vasica as an anti-arthritic agent.

\section{Acknowledgments}

The authors are grateful to the Principal Dr. Mrs. A. R. Madgulkar, AISSMS of Pharmacy, Pune for providing the necessary support and guidance.

\section{Refrences}

1. Remya Raju, Sigimol Joseph et al., 2012. Effect of the fractions of Erythrina stricta leaf extract on serum urate levels and $\mathrm{Xo} / \mathrm{Xdh}$ activities in oxonate-induced hyperuricaemic mice. Journal of Applied Pharmaceutical Science.; 2(02): 89-94.

2. Vikneswaran Murugaiyah, Kit-Lam et al (2009) Mechanisms of antihyperuricemic effect of Phyllanthus niruri and its lignan c onstituents Journal of Ethnopharmacology 124233-239.

3. Jingqun Huang a, Siwang Wang B et al., (2011) Effects of Genistein, Apigenin, Quercetin, Rutin and Astilbin on serum uric acid levels and xanthine oxidase activities in normal and hyperuricemic mice Food and Chemical Toxicology 49 1943-1947.

4. Yun-Wei Shi a, Cai-Ping et al., 2012Uricosuric and nephroprotective properties of Ramulus Moriethanol extract in hyperuricemic mice Journal of Ethnopharmacology
5. Ubonwan Pongprayoon Claesona et al., (2000) Review Adhatoda vasica: a critical review of ethnopharmacological and toxicological data Journal of Ethnopharmacology 72 1-20.

6. Pamela Gasse, Nicolas Riteau et al., 2010 Uric Acid Is a Danger Signal Activating NALP3 Inflammasome in Lung Injury Inflammation and Fibrosis.

7. Mohammad K. Mohammad, Rabab Taeem et al., 2010 Development of a new animal model-bioassay procedure for the evaluation of Xanthine oxidase inhibitors. Scientific Research and Essays Vol. 5(23), pp. 3750-375.

8. Jian-Mei Li, Xian Zhang et al., (2011) Protective effects of cortex fraxini coumarines against oxonateinduced hyperuricemia and renal dysfunction in mice European Journal of Pharmacology 666 196-204.

9. Patrick L. Owen a, *, Timothy Johns B et al.,(1999) Xanthine oxidase inhibitory activity of northeastern North American plant remedies used for gout. Journal of Ethnopharmacology 64 149-160.

10. J. Flemmig a, K. Kuchta B, et al., (2011) Olea europaea leaf (Ph.Eur.) extract as well as several of its isolated phenolicsinhibit the gout-related enzyme xanthine oxidase Phytomedicine 18561-566.

11. Santosh B. Mhaske, Narshinha P. Argade et al., (2006) The chemistry of recently isolated naturally occurring quinazolinone alkaloids Tetrahedron 62 9787-9826.

\section{How to cite this article:}

Pooja .S.Bhandare et al (2017) ' Preclinical Evaluation Of Herbal Plant In Potassium Oxonate Induced Hyperuricemia In Mice', International Journal of Current Advanced Research, 06(04), pp. 3357-3360.

DOI: http://dx.doi.org/10.24327/ijcar.2017.3360.0272 